\title{
Injuries of cattle and buffaloes during transportation and slaughter at Chittagong city corporation of Bangladesh
}

\author{
AKMH Kober*, MS Bari, MR Rakib, MS Ali \\ Department of Dairy and Poultry Science, Chittagong Veterinary and Animal Sciences University, Chittagong, \\ Bangladesh
}

\begin{abstract}
The study was conducted to ascertain the injuries of cattle and buffaloes at selected livestock markets of Bangladesh during transportation and slaughter. A total of 290 (212 cattle and 78 water buffalo) at Sagorica cattle market and 57 (24 cattle and 33 buffalo) at Fringibazar and Pahartali slaughter houses of Chittagong were examined during the period from January to April 2013. The frequency of different injuries during handling, transportation and slaughtering were assessed. The data of different type of injuries (e.g. abrasion, laceration, bleeding, swelling, scarification and wound) were collected from the market and slaughter houses by using visual observation and palpation method. The frequency of abrasion, laceration, bleeding, swelling and scarification of cattle were $73,45,4,3,67$ and $87 \%$, and of buffaloes were $71,9,23$ nd $41 \%$, respectively. All the injuries were higher in Haryana than Rajasthani, Shahiwal and Exotic non descriptive cattle breeds. The tail injury in cattle and buffaloes was 65 and $23 \%$, respectively. In the slaughter house, the frequency of abrasion, laceration, penetration and scarification were $79,75,8,75$ in cattle, and $85,70,0$ and $67 \%$ in buffaloes, respectively. From these findings it could be concluded that proper handling and care should be taken to avoid different injuries of cattle and buffaloes during transportation and slaughter.
\end{abstract}

Key words: Buffalo, cattle, transport, slaughter, injuries

Bangladesh Animal Husbandry Association. All rights reserved.

Bang. J. Anim. Sci. 2014. 43 (1): 74-77

Animal welfare $(A W)$ is a relatively new topic which is just beginning to attract attention in Bangladesh. The transports of farm animals for meat production in Bangladesh are mostly done by foot or in best cases by vehicle, usually during long distances. In addition, the road transport conditions involve high stocking densities, poor ventilation on the animals' underside, high humidity and temperatures, and crude forms of animal restraint, including the tying legs together, which may increase the risk of muscle injury, fatigue and stress. In Bangladesh, most of the slaughter houses are primitively structured poorly equipped and have an unhygienic environment. The personnel involved in slaughter houses regularly violate AW standards during slaughter. The attitude of most slaughter staff and butchers towards their animals are too negative. They don't have formal training to handle the animals for slaughtering. Transportation of livestock is an inevitable husbandry practices and can be a fatal stressor in animal (Kober et al. 2011). The animal industry is subjected to increase public scrutiny and criticism over the manner in which animals are transported for slaughter and other operation. When an animal is transported for slaughter there are several stages that each has the potential to cause injury. Specific criticism has been directed at the duration of journeys to the slaughter house. Majority of the people of Bangladesh are Muslim and their per capita meat consumption is lowest in the world (http://chartsbin.com/ view/12730). Every year huge number of culled draught cattle (mainly Haryana steers) and water buffaloes are imported from India. Normally 1618 cattle and $12-14$ buffaloes are loaded in a truck and it is obvious from visual inspection that there is overcrowding in relation to the surface area available for each animal (Alam et al. 2008). It takes normally 16-18 hour to reach Chittagong at Sagorica cattle market, sometimes due to strike, traffic jam or other problem this time is getting prolonged. These transport vehicles are open-top, no cushion is applied around the side to protect the injury. The animals are tied to the vehicles' sides to control their movement and ropes are secured at the neck, legs or nose. This condition leads to respiratory problems, discomfort, rubbing injuries, abrasion and laceration injuries from rubbing against the vehicle wall (Alam et al. 2010a). Skin injuries can also be associated with the down grading of meat and loss of skin value (Minka and Ayo 2007). The tail injuries occurred due to tail twisting, which is one of the methods to control the movement of 
animals such as cattle and water buffalo (Gregory et al. 2009). The other method is nose piercing frequently used in countries of Asia (Alam et al. 2010b). Loading and unloading can be two of the most stressful stages during animal transportation (Kober 2011). Inappropriate behavior by the animal handlers has often been observed, particularly at the time of unloading, involving the frequent use of sticks, which might explain some of the skin injuries. The animals don't get proper handling and care in the cattle market. Normally, animals are driven by feet to the slaughter house in the evening or night. A total number of 50-60 and 18-28 numbers of animals are daily slaughtered in Fringibazar and Pahartali slaughter house, respectively. In the slaughterhouse they are experiencing much more rough behavior than cattle market. The animals are frequently injured during the time of slaughter in their skin, muscles and bone. To the best of our knowledge, very few literatures are available regarding the welfare scenario of cattle and buffalo at livestock markets of Bangladesh during transport and slaughter. Therefore, the present study was undertaken for the assessment of injuries in cattle and buffaloes at selected livestock markets of Chittagong city in Bangladesh during transportation and slaughter.

The study was undertaken firstly in the Sagorica cattle market which is managed by the Chittagong City Corporation in Bangladesh. This is the second largest livestock market in Bangladesh, where cattle and water buffaloes from different regions of Bangladesh and imported from India are presented by local traders for sale to butchers in Chittagong areas. Secondly, two slaughter houses (Fringibazar slaughter house at Fringibazar and Pahartali slaughter house at Pahartali. The study was conducted during January to April, 2013.

In Sagorica cattle market, imported cattle and water buffaloes from India were considered. A total number of 212 cattle and 78 water buffaloes were randomly selected. In Fringibazar and Pahartali slaughter houses 14 and 10 cattle and 20 and 13 water buffaloes were selected respectively.

Among the selected animals, different injuries in the body area were inspected carefully, for example, abrasion, laceration, bleeding, swelling, penetration and scarification. In tail area, kinked tail and detailed condition were observed. Inspection and palpation methods of examination of animal were used to assess the physical condition of bodily injured animals (Figure 1-6). The following types of injuries were found in cattle market and slaughter houses.
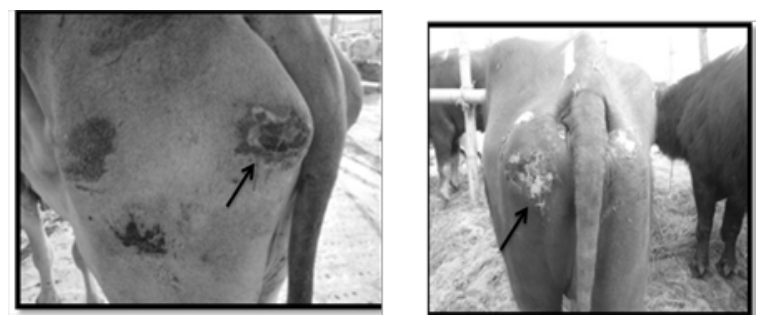

Figure 1. Abrasion
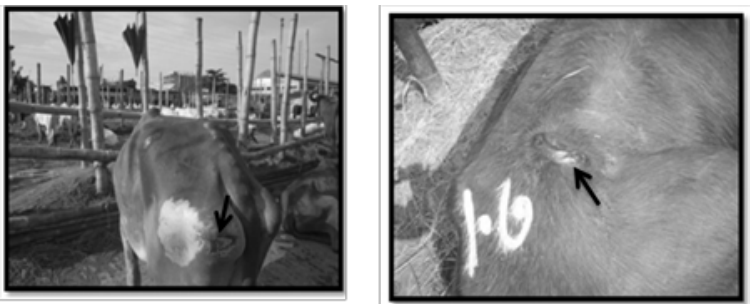

Figure 2. Laceration
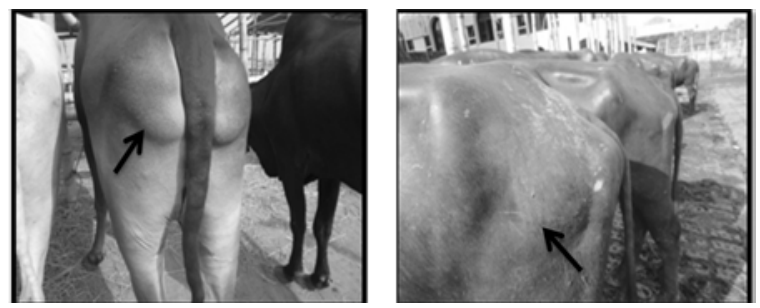

Figure 3. Swelling
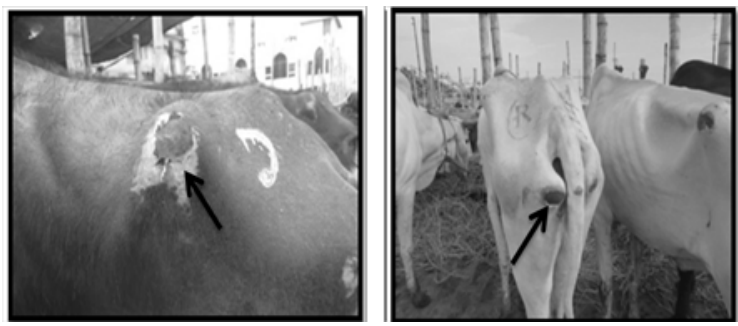

Figure 4. Scarification
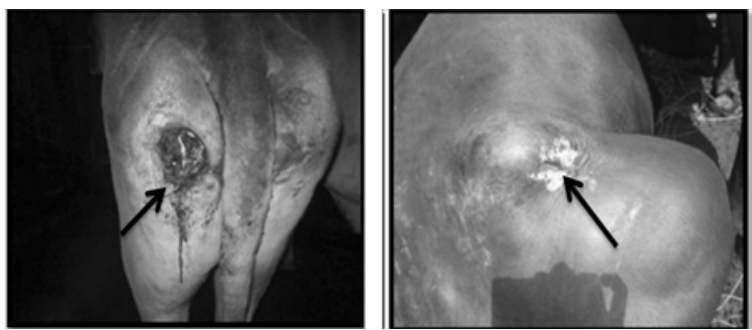

Figure 5. Penetrating injury 


\section{Injuries of cattle and buffaloes during transportation}
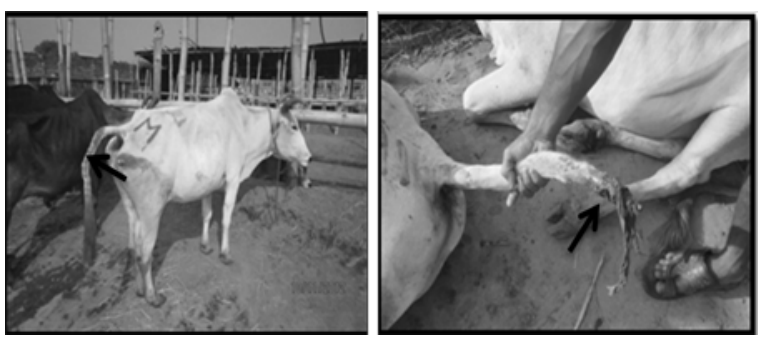

Figure 6. Kinked tail and detailed

In the present study, different categorical explanatory variables species, breed, skin injuries (abrasion, laceration, penetration, scarification, swelling) and tail injuries (kinked tail, detailed) were considered. The data were collected and obtained in Microsoft excel 2007 worksheet. The frequencies of different types of injuries regarding various variables were calculated by using SPSS 16 Software package.

Table 1. Different types of injuries in cattle and buffalo at Sagorica cattle market of Chittagong city

\begin{tabular}{|c|c|c|c|c|c|c|}
\hline Variable & $\begin{array}{l}\text { Animal } \\
\text { Type }\end{array}$ & A & on & ng & ing & car \\
\hline \multirow{2}{*}{ Species } & $\begin{array}{c}\text { Cattle } \\
(n=212)\end{array}$ & $\begin{array}{c}164 \\
(77.4 \%)\end{array}$ & $\begin{array}{c}124 \\
(58.5 \%)\end{array}$ & $\begin{array}{c}9 \\
(4.3 \%)\end{array}$ & $\begin{array}{c}8 \\
(3.8 \%)\end{array}$ & $\begin{array}{c}141 \\
(66.5 \%)\end{array}$ \\
\hline & $\begin{array}{l}\text { Buffalo } \\
(n=78)\end{array}$ & $\begin{array}{c}68 \\
(87.2 \%)\end{array}$ & $\begin{array}{c}55 \\
(70.5 \%) \\
\end{array}$ & $\begin{array}{c}7 \\
(9.0 \%) \\
\end{array}$ & $\begin{array}{c}18 \\
(23.1 \%)\end{array}$ & $\begin{array}{c}32 \\
(41.0 \%) \\
\end{array}$ \\
\hline \multirow{4}{*}{$\begin{array}{l}\text { Breeds } \\
\text { of cattle }\end{array}$} & $\begin{array}{l}\text { Haryana } \\
(n=159)\end{array}$ & $\begin{array}{c}129 \\
(81.1 \%)\end{array}$ & $\begin{array}{c}100 \\
(62.9 \%)\end{array}$ & $\begin{array}{c}7 \\
(4.4 \%)\end{array}$ & $\begin{array}{c}7 \\
(4.4 \%)\end{array}$ & $\begin{array}{c}123 \\
(77.4 \%)\end{array}$ \\
\hline & $\begin{array}{c}\text { Shahiwal } \\
(n=32)\end{array}$ & $\begin{array}{c}21 \\
(65.6 \%)\end{array}$ & $\begin{array}{c}13 \\
(40.6 \%)\end{array}$ & $\begin{array}{c}2 \\
(6.3 \%)\end{array}$ & $\begin{array}{c}1 \\
(3.1 \%)\end{array}$ & $\begin{array}{c}6 \\
(18.8 \%)\end{array}$ \\
\hline & $\begin{array}{c}\text { Rajasthani } \\
\quad(n=13)\end{array}$ & $\begin{array}{c}9 \\
(69.2 \%)\end{array}$ & $\begin{array}{c}6 \\
(46.2 \%)\end{array}$ & $\begin{array}{c}0 \\
(0.0 \%)\end{array}$ & $\begin{array}{c}0 \\
(0.0 \%)\end{array}$ & $\begin{array}{c}8 \\
(61.5 \%)\end{array}$ \\
\hline & $\begin{array}{c}\text { Exotic ND } \\
\quad(n=8)\end{array}$ & $\begin{array}{c}5 \\
(62.5 \%)\end{array}$ & $\begin{array}{c}5 \\
(62.5 \%)\end{array}$ & $\begin{array}{c}0 \\
(0.0 \%)\end{array}$ & $\begin{array}{c}0 \\
(0.0 \%)\end{array}$ & $\begin{array}{c}4 \\
(50.0 \%)\end{array}$ \\
\hline
\end{tabular}

ND, non descriptive

In case of cattle the frequencies of abrasion, laceration, bleeding and scar were higher and frequency of swelling was lower in the result of the present study than the result of Alam et al. (2010a). In case of buffalo the frequency of the laceration and scar was higher but the frequencies of abrasion, bleeding and swelling in the present study were lower than the finding of Alam et al. (2010a). In this study the frequency of abrasion was highest in Haryana breed and lowest in exotic non-descriptive (ND) cattle breed among the breeds of cattle. The frequency of the laceration was highest in both Haryana and exotic ND breed and lowest in Shahiwal cattle among the breeds of cattle (Table 1 ). The frequency of bleeding and swelling were higher in Haryana than Shahiwal within these two breeds of cattle. Among all the breeds of cattle the frequency of the scar was highest in Haryana breed and lowest in the Shahiwal breed as shown in Table 1.

The present study indicated that the frequency of kinked tail in cattle was higher than the buffalo. The frequency of detailed case was $23.08 \%$ in cattle whereas no such type of case was found in buffalo (Table 2). Among the breeds of cattle Haryana showed the highest frequency of kinked tail whereas Rajsthani showed the lowest. In case of the frequency of detailed case the Shahiwal breed showed the highest frequency but no cases of detailed tail were found in Rajsthani and exotic ND cattle. The frequency of kinked tail and detailed case were lower in the present findings than the findings of Alam et al. (2010b).

Table 2. Different types of tail injuries in cattle and water buffalo at Sagorica cattle market

\begin{tabular}{ccccc}
\hline \multirow{2}{*}{ Species } & \multirow{2}{*}{ Animal type } & No. of & \multicolumn{2}{c}{ Tail injured animals (No.) } \\
\cline { 3 - 5 } & & animals & Kinked tail & Detailed \\
\hline \multirow{4}{*}{ Cattle } & Haryana & 159 & $115(72.33)$ & $4(2.52)$ \\
& Shahiwal & 32 & $14(43.75)$ & $1(3.13)$ \\
& Rajasthani & 13 & $4(30.77)$ & 0 \\
& Exotic ND & 8 & $5(62.50)$ & 0 \\
& Total & 212 & $138(65.09)$ & $5(2.36)$ \\
\hline Water & Total & 78 & $18(23.08)$ & 0 \\
buffalo & Tot & & & 0 \\
\hline
\end{tabular}

ND, non descriptive; figures in the parentheses indicate the percent value

Table 3. Different types of injuries in cattle and water buffalo at Fringibazar and Pahartali slaughter houses

\begin{tabular}{lcccccc}
\hline \multirow{2}{*}{ Species } & \multirow{2}{*}{$\begin{array}{c}\text { Animal } \\
\text { type }\end{array}$} & $\begin{array}{c}\text { No. of } \\
\text { animals }\end{array}$ & Abrasion & \multicolumn{4}{c}{ Type of injury N (\%) } \\
\cline { 4 - 7 } & & Haceration & $\begin{array}{c}\text { Pene- } \\
\text { tration }\end{array}$ & Scar \\
\cline { 2 - 7 } & 22 & $\begin{array}{c}17 \\
(77.3)\end{array}$ & $\begin{array}{c}16 \\
(72.7)\end{array}$ & $\begin{array}{c}2 \\
(9.1)\end{array}$ & $\begin{array}{c}18 \\
(81.8)\end{array}$ \\
\hline \multirow{3}{*}{ Cattle } & Others & 2 & $\begin{array}{c}2 \\
(100)\end{array}$ & $\begin{array}{c}2 \\
(100.0)\end{array}$ & 0 & 0 \\
\cline { 2 - 7 } & Total & 24 & $\begin{array}{c}19 \\
(79.17)\end{array}$ & $\begin{array}{c}18 \\
(75.0)\end{array}$ & $2(8.3)$ & $\begin{array}{c}18 \\
(75.0)\end{array}$ \\
\hline Buffalo & - & 33 & $\begin{array}{c}28 \\
(84.9)\end{array}$ & $\begin{array}{c}23 \\
(69.7)\end{array}$ & 0 & $\begin{array}{c}22 \\
(66.7)\end{array}$ \\
\hline
\end{tabular}

$\mathrm{n}=57$; cattle $=24$; buffalo $=33$; figures in the parentheses indicate the percent value

Table 3 shows that in case of slaughter house injuries, the frequency of abrasion was higher in buffalo than cattle whereas the frequency of 
laceration, penetration and sear were higher in cattle in comparison to buffalo. Among the breeds of cattle the frequency of abrasion and laceration was higher in other breeds than Haryana whereas the frequency of penetration and scar were higher abin Haryana than other breeds of cattle. To our knowledge, no literatures are available regarding to slaughter house injuries, so comparing with other findings is quite difficult.

The cattle and water buffalo experienced an abrasion, laceration, scarification, swelling, penetration injury, kinked tail and detailed injuries and greater attention to be paid to handling methods of animals in Bangladesh during transport and slaughter.

\section{References}

Alam MR, Gregory NG, Jabbar MA, Uddin MS, Kibria ASMG, Silva-fletcher A (2010a). Skin injuries identified in cattle and water buffaloes at livestock markets in Bangladesh. Veterinary Record, 167: 415419.

Alam MR, Gregory NG, Uddin MS, Jabbar MA, Chowdhury S, Debnath NC (2010b). Frequency of nose and tail injuries in cattle and water buffaloes at livestock markets in Bangladesh. Animal Welfare, 19: 295-300.

Alam MR, Uddin MS, Kibria ASMG, Jabbar MA, Hassan MM, Sultana S (2008). Animal transport and slaughter: an animal welfare in Bangladesh. Proceedings of the Fifth Annual Scientific Conference of Chittagong Veterinary and Animal Sciences University, Chittagong, Bangladesh, 24-33.

Gregory NG, Benson T, Mason CW (2009). Cattle handling and welfare standards in livestock markets in the UK. Journal of Agricultural Science and Technology, 147: 345-354.

Kober AKMH (2011). Histological study of adrenal gland and its response to the transportation stress in chicken (Gallus domesticus), United Graduate School of Agricultural Science, Tokyo University of Agriculture and Technology, Japan Ph D thesis, 12-16.

Kober AKMH, Aoyama M, Tsukahara N, Sugita S (2011). The effects of acute transportation stress on the adrenal gland of the domestic chicken (Gallus domesticus). Animal Behaviour and Management, 47: 97-103.

Minka NS, Ayo, JO (2007). Effects of loading behavior and road transport stress on traumatic injuries in cattle transported by road during the hot-dry season. Livestock Science, 107: 91-95. 